\title{
Properties $P$ and $Q$ for Suzuki-type fixed point theorems in metric spaces
}

\author{
Renu Chugh, Raj Kamal and Madhu Aggarwal ${ }^{*}$ \\ Department of Mathematics, Maharshi Dayanand University,
}

Rohtak 124001

\begin{abstract}
The aim of this paper is to present several results for maps defined on a metric space involving contractive conditions of Suzuki-type which satisfy properties P and Q. An interesting fact about this study is that none of these maps has any nontrivial periodic points.
\end{abstract}

\section{Keywords}

Property P; Property Q; Metric space; Suzuki contraction.

\section{INTRODUCTION}

The Banach contraction principle [15] states that every contraction $T$ on a complete metric space has a unique fixed point. Recently, Suzuki [20] introduced a new type of mapping and presented a generalization of the Banach contraction principle as follows:

Theorem 1.1.[20] Define a non-increasing function $\theta$ from $[0,1)$ onto $\left(\frac{1}{2}, 1\right]$ by

$$
\theta(r)= \begin{cases}1 & \text { if } 0 \leq r \leq \frac{1}{2}(\sqrt{5}-1) \\ \frac{1-r}{r^{2}} & \text { if } \frac{1}{2}(\sqrt{5}-1) \leq r \leq \frac{1}{\sqrt{2}} \\ \frac{1}{1+r} & \text { if } \frac{1}{\sqrt{2}} \leq r<1 .\end{cases}
$$

Let $(X, d)$ be a complete metric space and let $T$ be a mapping from $X$ into itself. Assume that there exists $r \in[0,1)$ such that for all $x, y \in X$

$\theta(r) d(x, T x) \leq d(x, y)$ implies $d(T x, T y) \leq r d(x, y)$.

Then there exists a unique $z \in X$ such that $z \in T z$.

The elegant technique employed to prove Theorem 1.1 attracted several authors to work along these lines and subsequently Theorem 1.1 was generalized and extended in various ways (see for instance, [1], [3], [4], [7-14], [16-19], [21], [22] and others).

We will denote the set all fixed points of a self mapping $\mathrm{T}$ from $X$ into itself by $\mathrm{F}(\mathrm{T})$, i.e., $\mathrm{F}(\mathrm{T})=\{\mathrm{z} \in \mathrm{X}: \mathrm{Tz}=\mathrm{z}\}$. It is obvious that if $z$ is a fixed point of $T$ then it is also a fixed point of $T^{n}$ for each $n \in N, i$. e., $F(T) \subset F\left(T^{n}\right)$ if $F(T) \neq \phi$. However converse is false. Indeed the mapping $\mathrm{T}: \mathrm{R} \rightarrow \mathrm{R}$ defined by $\mathrm{T} x=\frac{1}{2}-x$ has a unique fixed point, i.e., $\mathrm{F}(\mathrm{T})=$ $\left\{\frac{1}{4}\right\}$, but every $\mathrm{x} \in \mathrm{R}$ is a fixed point for $\mathrm{T}^{2}$. If $F(T)=F\left(T^{n}\right)$, for each $n \in N$, then we say that $\mathrm{T}$ has no periodic points.

In 2005, Jeong and Rhoades [5] examine a number of situations in which the fixed point sets for maps and their iterates are the same.

They state that a map $T$ has property $\boldsymbol{P}$ if $\mathrm{F}(T)=\mathrm{F}\left(T^{n}\right)$ for each $n \in N$. Also a pair of maps $S$ and $T$ have property $Q$ if $\mathrm{F}(S) \cap \mathrm{F}(T)=\mathrm{F}\left(S^{n}\right) \cap \mathrm{F}\left(T^{n}\right)$ for each $n \in N$.
Several works has been done related to Property $\mathrm{P}$ and $\mathrm{Q}$ (see for instance [2] and [6]).

Now we continue this study for mappings satisfying Suzuki type contractive conditions in metric space. In section I, we discuss property $P$ for a map which involve Suzuki contractive conditions. In section II, we prove property $Q$ for pairs of maps involving above contractive conditions. An important of this study is that if a map satisfies property $\mathrm{P}$ then every periodic point is a fixed point. The same situation is true for maps satisfying property $\mathrm{Q}$.

\section{PROPERTY $P$}

Theorem 2.1.Define a nonincreasing function $\varphi$ from $[0,1)$ into $(0,1]$ by

$$
\varphi(r)= \begin{cases}1, & \text { if } 0 \leq r \leq \frac{1}{2} \\ 1-r, & \text { if } \frac{1}{2} \leq r \leq 1 .\end{cases}
$$

Let $(X, d)$ be a complete metric space and let $T$ be a mapping from $X$ into itself. Assume that there exists $r \in[0$, 1) such that for all $x, y \in X$ $\varphi(r) d(x, T x) \leq d(x, y)$ implies

$$
d(T x, T y) \leq r \max \left\{\begin{array}{l}
d(x, y), d(x, T x), d(y, T y), \\
\frac{d(x, T y)+d(y, T x)}{2}
\end{array}\right\} .
$$

Then $T$ has property $P$.

Proof:From corollary 2.3 of [3], $T$ has a fixed point. In other words, $\mathrm{F}(T) \neq \emptyset$. Therefore $\mathrm{F}\left(T^{m}\right) \neq \varnothing$ for each positive integer $m$.Let $n$ be a fixed positive integer greater than 1 and suppose that $z \in F\left(T^{n}\right)$. We claim that $z \in F(T)$, that is, $z$ is a fixed point of $T$.

Suppose that $z \neq T z$. Then

$d(z, T z)=d\left(T^{n} z, T\left(T^{n} z\right)\right)=d\left(T^{n} z, T^{n+1} z\right)$,

which is of the form $d(T x, T y)$, here

$y=T^{n} z, x=T^{n-1} z$.

Now $\varphi(r) d(x, T x)=\varphi(r) d\left(T^{n-1} z, T\left(T^{n-1} z\right)\right)$

$$
=\varphi(r) d\left(T^{n-1} z, T^{n} z\right) \leq d(x, y),
$$

that is, $\quad \varphi(r) d(x, T x) \leq d(x, y)$ implies

$d(T x, T y) \leq r \max \left\{\begin{array}{l}d(x, y), d(x, T x), d(y, T y), \\ \frac{d(x, T y)+d(y, T x)}{2}\end{array}\right\}$

that is, $d\left(T\left(T^{n-1} z\right), T\left(T^{n} z\right)\right)$

$\leq r \max \left\{\begin{array}{l}d\left(T^{n-1} z, T^{n} z\right), d\left(T^{n-1} z, T^{n} z\right), d\left(T^{n} z, T^{n+1} z\right), \\ \frac{d\left(T^{n-1} z, T^{n+1} z\right)+d\left(T^{n} z, T^{n} z\right)}{2}\end{array}\right\}$,

$=r \max \left\{d\left(T^{n-1} z, T^{n} z\right), d\left(T^{n} z, T^{n+1} z\right), \frac{d\left(T^{n-1} z, T^{n+1} z\right)}{2}\right\}$, 
thatis, $d\left(T^{n} z, T^{n+1} z\right) \leq r \max$

$\leq r \max \left\{d\left(T^{n-1} z, T^{n} z\right), d\left(T^{n} z, T^{n+1} z\right)\right\}$.

Then $d\left(T^{n} z, T^{n+1} z\right) \leq r d\left(T^{n-1} z, T^{n} z\right)$.

Continuing like this, we have

$d\left(T^{n} z, T^{n+1} z\right) \leq r d\left(T^{n-1} z, T^{n} z\right) \leq r^{2} d\left(T^{n-2} z, T^{n-1} z\right) \leq \ldots \ldots . . \leq$

$r^{n} d(z, T z)$,

that is, $\quad d(z, T z) \leq r^{n} d(z, T z)<d(z, T z)$,

that is, $\quad d(z, T z)<d(z, T z)$,

which is a contradiction.

So our supposition that $z \neq T z$ is wrong.Thus, $z=T z$ and so $z \in F(T)$.

Therefore $F\left(T^{n}\right) \subseteq F(T)$.Also $F(T) \subseteq F\left(T^{n}\right)$.

Thus, $\mathrm{F}(T)=F\left(T^{n}\right)$. Hence $T$ satisfies property $P$.

Special cases of Theorem 2.1 are contractive conditions appearing in Theorem 3.3 of [19], Theorem 2.2 and Theorem 3.1 of [8], Theorem 2 of [20], Corollary 3.4 of [17] and Corollary 4.4 of [18].

Theorem 2.2. Let $(X, d)$ be a compact metric space and let $T$ be a mapping on $X$. Assume that

$\frac{1}{2} d(x, T x)<d(x, y)$ implies $d(T x, T y)<d(x, y)$

for $x, y \in X$. Then $T$ has property $P$.

Proof: From Theorem 3 of [21], T has a unique fixed point.In other words, $\mathrm{F}(T) \neq \varnothing$. Therefore $\mathrm{F}\left(T^{m}\right) \neq \varnothing$ for each positive integer $m$.Let $n$ be a fixed positive integer greater than 1 and suppose that $z \in F\left(T^{n}\right)$.We claim that $z \in F(T)$, that is, $z$ is a fixed point of $T$.

Suppose that $z \neq T z$. Then

$d(\mathrm{z}, \mathrm{Tz})=d\left(T^{n} z, T\left(T^{n} z\right)\right)=d\left(T^{n} z, T^{n+1} z\right)$,

which is of the form $d(T x, T y)$, here $y=T^{n} z, x=T^{n-1} z$.

Now $\frac{1}{2} d(x, T x)=\frac{1}{2} d\left(T^{n-1} z, T\left(T^{n-1} z\right)\right)=\frac{1}{2} d\left(T^{n-1} z, T^{n} z\right)$

$<d\left(T^{n-1} z, T^{n} z\right)$,

that is, $\frac{1}{2} d(x, T x)<d(x, y)$ implies $d(T x, T y)<d(x, y)$,

that is, $d\left(T\left(T^{n-1} z\right), T\left(T^{n} z\right)\right)<d\left(T^{n-1} z, T^{n} z\right)$,

that is, $d\left(T^{n} z, T^{n+1} z\right)<d\left(T^{n-1} z, T^{n} z\right)$.

Continuing like this, we have

$d\left(T^{n} z, T^{n+1} z\right)<d(z, T z)$,

That is, $d(z, T z)<d(z, T z)$, which is a contradiction.

So our supposition that $z \neq T z$ is wrong. Thus, $z=T z$ and so $z \in F(T)$.

Therefore $F\left(T^{n}\right) \subseteq F(T)$.Also $F(\mathrm{~T}) \subseteq F\left(T^{n}\right)$.

Thus, $F(\mathrm{~T})=F\left(T^{n}\right)$.Hence $T$ satisfies property $P$.

Theorem 2.3: Define a function $\eta$ from $[0,1)$ into $(1 / 2,1]$ by

$$
\eta(r)=\left\{\begin{array}{ccc}
1 & \text { if } & 0 \leq r<1 / 2 \\
(1+r)^{-1} & \text { if } & 1 / 2 \leq r<1
\end{array}\right\} .
$$

Let $(X, d)$ be a complete metric space and let $T$ be a mappings form $X$ into $\mathrm{CB}(\mathrm{X})$. Assume that there exists $r \in$ $[0,1)$ such that for all $x, y \in X$

$\eta(r) d(x, T x) \leq d(x, y)$ implies $\delta(T x, T y) \leq r d(x, y)$.
Proof: From theorem 4 of [10], $T$ has a unique fixed point $\mathrm{z}$ and $T z=\{z\}$. Therefore, $\mathrm{F}\left(T^{n}\right) \neq \phi$ for each positive integer $n$. Let $n$ be a fixed positive integer greater than 1 and suppose that $u \in F\left(T^{n}\right)$. We claim that $u \in F(T)$, that is, $u$ is a fixed point of $T$.

Let $u \in F\left(T^{n}\right)$ Then for any positive integer $i, j$ satisfying $0 \leq$ $i, j \leq n$, we obtain

$$
\begin{aligned}
& \eta(r) d\left(T^{i-1} u, T\left(T^{j-1} u\right)\right)=\eta(r) d\left(T^{i-1} u, T^{j} u\right) \leq \\
& d\left(T^{i-1} u, T^{j} u\right) .
\end{aligned}
$$

Then contractive condition (2.3.1) implies that $\delta\left(T\left(T^{i-1} u\right), T\left(T^{j} u\right)\right) \leq r d\left(T^{i-1} u, T^{j} u\right)$. (2.3.2)

Define $\delta=\max _{0 \leq i, j \leq n} \delta\left(T^{i} u, T^{j} u\right)$.

Since, if $j=n$, then $T^{j+1} u=T u$.

Assuming $\delta>0$, it then follows from (2.3.2) that $\delta \leq r \delta$, which is a contradiction.

Therefore $\delta=0$. Thus $\delta(T u, u)=0$ implies $\{u\}=T u$. Hence $u \in \mathrm{F}(T)$.

Hence $T$ satisfies property $P$.

\section{PROPERTY Q}

Theorem 3.1. Define a strictly decreasing function $\eta$ from $[0,1)$ onto $\left(\frac{1}{2}, 1\right]$ by $\eta(r)=\frac{1}{1+r}$.

Let $(X, d)$ be a complete metric space and let $T$ and $S$ be mappings from $X$ into itself. Assume that there exists $r \in[0,1)$ such that for all $x, y \in X$

Sy) $\leq r M(x, y)$ $\eta(r) \min \{d(x, T x), d(y, S y)\} \leq d(x, y)$ implies $d(T x$,

where $M(x, y)=\max \left\{\begin{array}{l}d(x, y), \frac{d(x, T x)+d(y, S y)}{2}, \\ \frac{d(x, S y)+d(y, T x)}{2}\end{array}\right\}$

Then $S$ and $T$ have property Q.

Proof: From corollary 2.3 of [12], $S$ and $T$ have a unique common fixed point. In other words, $\mathrm{F}(S) \cap \mathrm{F}(T) \neq \emptyset$.

Therefore, $\mathrm{F}\left(S^{m}\right) \cap \mathrm{F}\left(T^{m}\right) \neq \emptyset$ for each positive integer $m$. Let $n$ be a fixed positive integer greater then 1and suppose that $z \in \mathrm{F}\left(S^{n}\right) \cap \mathrm{F}\left(T^{n}\right)$.

We claim that $z \in \mathrm{F}(S) \cap \mathrm{F}(T)$. To prove this,it is sufficient to show that $z$ is a fixed point of $T$.

Suppose that $z \neq T z$. Then

$d(z, T z)=d\left(S^{n} z, T\left(T^{n} z\right)\right)=d\left(T\left(T^{n} z\right), S\left(S^{n-1} z\right)\right)$,

which is of the form $d(T x, S y)$, here $x=T^{n} z, y=S^{n-1} z$.

Now $\eta(r) d(x, T x)=$

$\eta(r) d\left(T^{n} z, T\left(T^{n} z\right)\right)=\eta(r) d\left(T^{n} z, T^{n+1} z\right)$

$$
\leq d\left(T^{n} z, T^{n+1} z\right)
$$

Case-I If $d(x, T x) \leq d(y, S y)$

Then $d\left(T^{n} z, T^{n+1} z\right) \leq d\left(S^{n-1} z, S^{n} z\right)=d\left(S^{n-1} z, z\right)$

$=d\left(S^{n-1} z, T^{n} z\right)=d\left(\mathrm{~T}^{\mathrm{n}} \mathrm{z}, \mathrm{S}^{\mathrm{n}-1} \mathrm{z}\right) . \quad(3.1 .3)$

Combining (3.1.2) and (3.1.3) we have

$\eta(r) d(x, T x) \leq d(x, y)$.

Then by contractive condition (3.1.1), we have

$d(T x, S y) \leq r \max \left\{\begin{array}{l}d(x, y), \frac{d(x, T x)+d(y, S y)}{2}, \\ \frac{d(x, S y)+d(y, T x)}{2}\end{array}\right\}$.

Then $T$ has property $P$. 
This implies that $d\left(T\left(T^{n} z\right), S\left(S^{n-1} z\right)\right) \leq$

$r \max \left\{\begin{array}{l}d\left(T^{n} z, S^{n-1} z\right), \frac{d\left(T^{n} z, T^{n+1} z\right)+d\left(S^{n-1} z, S^{n} z\right)}{2}, \\ \frac{d\left(T^{n} z, S^{n} z\right)+d\left(S^{n-1} z, T^{n+1} z\right)}{2}\end{array}\right\}$,

That is, $d\left(T^{n+1} z, S^{n} z\right) \leq$

$r \max \left\{\begin{array}{l}d\left(T^{n} z, S^{n-1} z\right), \frac{d\left(T^{n} z, T^{n+1} z\right)+d\left(S^{n-1} z, S^{n} z\right)}{2}, \\ \frac{d\left(T^{n} z, S^{n} z\right)+d\left(S^{n-1} z, T^{n+1} z\right)}{2}\end{array}\right\}$.

Case-II If $d(y, S y) \leq d(x, T x)$,

i.e. $d\left(S^{n-1} z, S\left(S^{n-1} z\right) \leq d\left(T^{n} z, T\left(T^{n} z\right)\right)\right.$,

i.e. $d\left(S^{n-1} z, S^{n} z\right) \leq d\left(T^{n} z, T^{n+1} z\right)$,

Now $(r) d(y, S y)=\eta(r) d\left(S^{n-1} z, S^{n} z\right) \leq d\left(S^{n-1} z, S^{n} z\right)=$ $d\left(S^{n-1} z, z\right)$

$$
=d\left(S^{n-1} z, T^{n} z\right)=d(x, y) .
$$

As $d(y, S y) \leq d(x, T x)$ and $\eta(r) d(y, S y) \leq d(x, y)$

So by contractive condition (3.1.1), we have

$d(T x, S y) \leq r \max r \max \left\{\begin{array}{l}d(x, y), \frac{d(x, T x)+d(y, S y)}{2}, \\ \frac{d(x, S y)+d(y, T x)}{2}\end{array}\right\}$.

This implies that $d\left(T\left(T^{n} z\right), S\left(S^{n-1} z\right)\right) \leq$

$r \max \left\{\begin{array}{l}d\left(T^{n} z, S^{n-1} z\right), \frac{d\left(T^{n} z, T^{n+1} z\right)+d\left(S^{n-1} z, S^{n} z\right)}{2}, \\ \frac{d\left(T^{n} z, S^{n} z\right)+d\left(S^{n-1} z, T^{n+1} z\right)}{2}\end{array}\right\}$,

that is, $d\left(T^{n+1} z, S^{n} z\right) \leq$

$r \max \left\{\begin{array}{l}d\left(T^{n} z, S^{n-1} z\right), \frac{d\left(T^{n} z, T^{n+1} z\right)+d\left(S^{n-1} z, S^{n} z\right)}{2}, \\ \frac{d\left(T^{n} z, S^{n} z\right)+d\left(S^{n-1} z, T^{n+1} z\right)}{2}\end{array}\right\}$.

Thus from bothcase-I and case-II, we obtain $d\left(T^{n+1} z, S^{n} z\right) \leq$

$r \max \left\{\begin{array}{l}d\left(T^{n} z, S^{n-1} z\right), \frac{d\left(T^{n} z, T^{n+1} z\right)+d\left(S^{n-1} z, S^{n} z\right)}{2}, \\ \frac{d\left(T^{n} z, S^{n} z\right)+d\left(S^{n-1} z, T^{n+1} z\right)}{2}\end{array}\right\}$,

that is, $\quad d(z, T z) \leq$

$r \max \left\{\begin{array}{l}d\left(z, S^{n-1} z\right), \frac{d(z, T z)+d\left(S^{n-1} z, z\right)}{2}, \\ \frac{d(z, z)+d\left(S^{n-1} z, T z\right)}{2}\end{array}\right\}$,

that is, $d(z, T z) \leq r \max$ $r \max \left\{d\left(z, S^{n-1} z\right), \frac{d(z, T z)+d\left(S^{n-1} z, z\right)}{2}, \frac{d\left(S^{n-1} z, T z\right)}{2}\right\}$.

Since, $\frac{d\left(S^{n-1} z, T z\right)}{2} \leq \frac{d(z, T z)+d\left(S^{n-1} z, z\right)}{2}$.

So (3.1.4) takes the form

$d(z, T z) \leq r \max \left\{d\left(z, S^{n-1} z\right), \frac{d(z, T z)+d\left(S^{n-1} z, z\right)}{2}\right\}$.

Case-(a) If $d(z, T z) \leq r d\left(z, S^{n-1} z\right)$.
Case-(b) If $d(z, T z) \leq r \frac{d(z, T z)+d\left(S^{n-1} z, z\right)}{2}$.

that is, $2 d(z, T z) \leq r d(z, T z)+r d\left(S^{n-1} z, z\right)$,

$(2-r) d(z, T z) \leq r d\left(S^{n-1} z, z\right)$,

$d(z, T z) \leq\left(\frac{r}{2-r}\right) d\left(S^{n-1} z, z\right)$,

that is, $d(z, T z) \leq r_{1} d\left(S^{n-1} z, z\right)$, where $r_{1}<1$.

Thus from case-(a) and case-(b), we have

$$
d(z, T z) \leq \beta d\left(S^{n-1} z, z\right), \text { where } \beta<1,
$$

that is, $d(T z, z) \leq \beta d\left(z, S^{n-1} z\right)$,

that is, $d\left(T\left(T^{n} z\right), S^{n} z\right) \leq \beta d\left(T^{n} z, S^{n-1} z\right)$.

Thus we get $d\left(T^{n+1} z, S^{n} z\right) \leq \beta d\left(T^{n} z, S^{n-1} z\right)$

Continuing like this, we have

$$
d\left(T^{n+1} z, S^{n} z\right) \leq \beta^{n} d(T z, z)<d(T z, z),
$$

that is, $d(T z, z)<d(T z, z)$, which is a contradiction. So, oursupposition that $z \neq T z$ is wrong. Thus $z=T z$. Analogouslyz $=S z$. Therefore $z \in \mathrm{F}(T) \cap \mathrm{F}(S)$.

So $\mathrm{F}\left(S^{n}\right) \cap \mathrm{F}\left(T^{n}\right) \subseteq \mathrm{F}(T) \cap \mathrm{F}(S)$.

Also $\mathrm{F}(T) \cap \mathrm{F}(S) \subseteq \mathrm{F}\left(S^{n}\right) \cap \mathrm{F}\left(T^{n}\right)$.

Thus, $\mathrm{F}(T) \cap \mathrm{F}(S)=\mathrm{F}\left(S^{n}\right) \cap \mathrm{F}\left(T^{n}\right)$.

Hence $S$ and $T$ satisfy property Q.

Theorem 3.2. Define a non-increasing function $\theta$ as in Theorem 1.1 and let $X$ be a complete metric space, $f, T: \mathrm{X} \rightarrow$ $X$ satisfying the following:

(i) $f$ is continuous.

(ii) $T(X) \subset f(X)$.

(iii) fand $T$ commute

Assume there exists $r \in[0,1)$ such that for each $x, y \in X$, $\theta(r) d(f x, T x) \leq d(f x, f y)$ implies

$d(T x, T y) \leq r \max \left\{\begin{array}{l}d(f x, f y), d(f x, T x), d(f y, T y), \\ \frac{d(f x, T y)+d(f y, T x)}{2}\end{array}\right\}$.

Then $f$ and $T$ have property Q.

Proof: From theorem 2.1 of [11], $f$ and $T$ have a unique common fixed point.

In other words, $\mathrm{F}(f) \cap \mathrm{F}(T) \neq \emptyset$. Therefore $\mathrm{F}\left(f^{n}\right) \cap \mathrm{F}\left(T^{n}\right) \neq \varnothing$ for each positive integer $n$. Let $n$ be a fixed positive integer greater than 1 and suppose that $u \in \mathrm{F}\left(f^{n}\right) \cap \mathrm{F}\left(T^{n}\right)$. We claim that

$u \in \mathrm{F}(f) \cap \mathrm{F}(T)$

Since $u \in \mathrm{F}\left(f^{n}\right) \cap \mathrm{F}\left(T^{n}\right)$. Then for any positive integer $i, r$ satisfying $0 \leq i, r \leq n$, we obtain

$\theta(r) d\left(f\left(T^{i-1} f^{r-1} u\right), T\left(T^{i-1} f^{r-1} u\right)\right)$

$\leq d\left(T^{i-1} f^{r} u, T^{i} f^{r-1} u\right)$

$=d\left(f\left(T^{i-1} f^{r-1} u\right), f\left(T^{i} f^{r-2} u\right)\right)$.

Then contractive condition (3.2.1) implies that

$d\left(T^{i} f^{r-1} u, T^{i+1} f^{r-2} u\right) \leq$

$r \max \left\{\begin{array}{l}d\left(T^{i-1} f^{r} u, T^{i} f^{r-1} u\right), d\left(T^{i-1} f^{r} u, T^{i} f^{r-1} u\right), \\ d\left(T^{i} f^{r-1} u, T^{i+1} f^{r-2} u\right), \\ \frac{d\left(T^{i-1} f^{r} u, T^{i+1} f^{r-2} u\right)+d\left(T^{i} f^{r-1} u, T^{i} f^{r-1} u\right)}{2}\end{array}\right\}$ 
Define $\delta=\max _{0 \leq i, r, l, t \leq n} d\left(T^{i} f^{r} u, T^{l} f^{t} u\right)$

Since, if $i=n$, then $T^{i+1} u=T u$.

Assuming $\delta>0$, it then follows from (3.2.2) that $\delta \leq r \max \{\delta, \delta, \delta, \delta\}$,

that is, $\delta<\delta$ which is a contradiction. Therefore $\delta=0$.

Thus $d(f u, u)=\mathrm{d}(T u, u)=0$ implies $u=f u=T u$.

Hence $u \in \mathrm{F}(f) \cap \mathrm{F}(T)$.

So $\mathrm{F}\left(f^{n}\right) \cap \mathrm{F}\left(T^{n}\right) \subseteq \mathrm{F}(f) \cap \mathrm{F}(T)$.

Also $\mathrm{F}(f) \cap \mathrm{F}(T) \subseteq \mathrm{F}\left(f^{n}\right) \cap \mathrm{F}\left(T^{n}\right)$.

Thus, $\mathrm{F}(f) \cap \mathrm{F}(T)=\mathrm{F}\left(f^{n}\right) \cap \mathrm{F}\left(T^{n}\right)$.

Hence $f$ and $T$ satisfy property $\mathrm{Q}$.

Special case of Theorem 3.2 is contractive condition appearing in Theorem 3 of [7].

Theorem 3.3.Let $(X, d)$ be a complete metric space. Let $f$ and $T$ be mappings on $X$ satisfying

(i)-(iii) in Theorem 3.2. Assume that

$\frac{1}{2} d(f x, T x)<d(f x, f y)$ implies

$d\left(T x, T y<\max \left\{d(f x, f y), \frac{d(f x, T x)+d(f y, T y)}{2}\right\}\right.$

for all $x, y \in X$, and that for any $\epsilon>0$, there exists $\delta(\epsilon)>0$ such that for all $x, y \in X$

$\frac{1}{2} d(f x, T x)<d(f x, f y)$ and $\max$

$\max \left\{d(f x, f y), \frac{d(f x, T x)+d(f y, T y)}{2}\right\}<\epsilon+\delta(\epsilon)$

implies $d(T x, T y) \leq \epsilon$.

Then $f$ and $T$ have property Q.

Proof: From theorem 3.1 of [11], $f$ and $T$ have a unique common fixed point.

In other words, $\mathrm{F}(f) \cap \mathrm{F}(T) \neq \varnothing$. Therefore $\mathrm{F}\left(f^{n}\right) \cap \mathrm{F}\left(T^{n}\right) \neq \varnothing$

for each positive integer $n$. Let $n$ be a fixed positive integer greater than 1 and suppose that $u \in \mathrm{F}\left(f^{n}\right) \cap \mathrm{F}\left(T^{n}\right)$. We claim that $u \in \mathrm{F}(f) \cap \mathrm{F}(T)$.

Since $u \in \mathrm{F}\left(f^{n}\right) \cap \mathrm{F}\left(T^{n}\right)$. Then for any positive integer $i, r$ satisfying $0 \leq i, r \leq n$, we obtain

$\frac{1}{2} d\left(f\left(T^{i-1} f^{r-1} u\right), T\left(T^{i-1} f^{r-1} u\right)\right)<d\left(T^{i-1} f^{r} u, T^{i} f^{r-1} u\right)$

$=d\left(f\left(T^{i-1} f^{r-1} u\right), f\left(T^{i} f^{r-2} u\right)\right)$.

Then contractive condition (3.3.1) implies that

$$
\begin{aligned}
& d\left(T^{i} f^{r-1} u, T^{i+1} f^{r-2} u\right) \\
& <\max \left\{\begin{array}{l}
d\left(T^{i-1} f^{r} u, T^{i} f^{r-1} u\right), \\
\frac{d\left(T^{i-1} f^{r} u, T^{i} f^{r-1} u\right)+d\left(T^{i} f^{r-1} u, T^{i+1} f^{r-2} u\right)}{2}
\end{array}\right\}
\end{aligned}
$$

Define $\delta=\max _{0 \leq i, r, l, t \leq n} d\left(T^{i} f^{r} u, T^{l} f^{t} u\right)$

Since, if $i=n$, then $T^{i+1} u=T u$.

Assuming $\delta>0$, it then follows from (3.3.2) that $\delta<\max \{\delta, \delta\}$,

that is, $\delta<\delta$ which is a contradiction. Therefore $\delta=0$.

Thus $d(f u, u)=\mathrm{d}(T u, u)=0$ implies $u=f u=T u$.

Hence $u \in \mathrm{F}(f) \cap \mathrm{F}(T)$.
So $\mathrm{F}\left(f^{n}\right) \cap \mathrm{F}\left(T^{n}\right) \subseteq \mathrm{F}(f) \cap \mathrm{F}(T)$.

Also $\mathrm{F}(f) \cap \mathrm{F}(T) \subseteq \mathrm{F}\left(f^{n}\right) \cap \mathrm{F}\left(T^{n}\right)$.

Thus, $\mathrm{F}(f) \cap \mathrm{F}(T)=\mathrm{F}\left(f^{n}\right) \cap \mathrm{F}\left(T^{n}\right)$.Hence $f$ and $T$ satisfy property Q.

Special case of Theorem 3.3 is Meir-Keeler contractive condition appearing in Theorem 4 of [7].

\section{CONCLUSION}

In this paper, we have studied a number of Suzuki-type contractive conditions defined on a metric space for which fixed point sets for maps and their iterates are same. An important fact about this study is that if maps satisfy property $\mathrm{P}$ or $\mathrm{Q}$ then every periodic point is a fixed point.

\section{REFERENCES}

[1] B. Damjanović and D. Dorić, Multivalued generalizations of the Kannan fixed point theorem, Filomat, vol. 25 (1) , DOI: 10.2298/FIL 1101125D, (2011), 125-131.

[2] B. E. Rhoades and M. Abbas, Maps satisfying generalized contractive condition of integral type for which $\mathrm{F}(\mathrm{T})=\mathrm{F}\left(\mathrm{T}^{\mathrm{n}}\right)$, International Journal of Pure and Applied Mathematics, vol. 45, no. 2 (2008), 225-231.

[3] D. Dorić and R. Lazović, Some Suzuki-type fixed point theorems for generalized multivalued mappings and applications, Fixed Point Theory and Appl.,2011:40, (2011), 13 pp.

[4] G. Moţ and A. Petruşel, Fixed point theory for a new type of contractive multi-valued operators, Nonlinear Anal., 70(9), (2009), 3371-3377.

[5] G. S. Jeong and B. E. Rhoades, Maps for which $\mathrm{F}(\mathrm{T})=$ $\mathrm{F}\left(\mathrm{T}^{\mathrm{n}}\right)$, Fixed Point Theory and Appl., vol. 6(2005), 169.

[6] G. S. Jeong and B. E. Rhoades, More maps for which $\mathrm{F}(\mathrm{T})=\mathrm{F}\left(\mathrm{T}^{\mathrm{n}}\right)$, DemonstratioMathematica, vol. $\mathrm{XL}$, no. 3 (2007), 671-680.

[7] M. Kikkawa and T. Suzuki, Three fixed point theorems for generalized contractions with constants in complete metric spaces,Nonlinear Anal., 69(9), (2008), 2942 2949.

[8] M. Kikkawa and T. Suzuki, Some similarity between contractions and Kannan mappings, Fixed Point Theory and Appl., vol. 2008,Art.ID 649749, (2008), 8 pp.

[9] M. Kikkawa and T. Suzuki, Some similarity between contractions and Kannan mappings II, Bull. Kyushu Inst. Technol. Pure Appl. Math,.no. 55 (2008), 1-13.

[10] M. Kikkawa and T. Suzuki, Some notes on fixed point theorems with constants,Bull. Kyushu Inst. Technol. Pure Appl. Math,.no. 56 (2009), 11-18.

[11] O. Popescu, Two fixed point theorems for generalized contractions with constants in complete metric space, Cent. Eur. J. Math., 7(3), (2009), 529-538.

[12] Raj Kamal, Renu Chugh, ShyamLal Singh and Swami Nath Mishra, New common fixed point theorems for multivalued maps, Applied general topology, Accepted.

[13] R. Kannan, Some results on fixed points,Bull. Calcutta Math. Soc.,60 (1968), 71-76. 
[14] R. Kannan, Some results on fixed points. II,Amer. Math. Monthly, 76 (1969), 405-408.

[15] S. Banach, Sur les operations dans les ensembles abstraitsetleur application aux equations integrales, Fund. Math., 3 (1922), 133-181.

[16] S. L. Singh, H. K. Pathak and S. N. Mishra, On a Suzuki type general fixed point theorem with applications, Fixed Point Theory and Appl.,vol. 2010, Art. ID 234717, (2010), 15 pp.

[17] S. L. Singh and S. N. Mishra, Coincidence theorems for certain classes of hybrid contractions,Fixed Point Theory and Appl., vol.2010,Art. ID 898109, (2010), 14 pp.

[18] S. L. Singh and S. N. Mishra, Remarks on recent fixed point theorems,Fixed Point Theory and Appl.,vol. 2010,Art. ID 452905, (2010), 18 pp.
[19] S. Dhompongsa and H. Yingtaweesittikul, Fixed points for multivalued mappings and the metric completeness,Fixed Point Theory and Appl., vol.2009,Art. ID 972395, (2009), 15 pp.

[20] T. Suzuki, A generalized Banach contraction principle that characterizes metric completeness, Proc. Amer. Math. Soc., vol. 136, no. 5, (2008), 1861-1869.

[21] Tomonari Suzuki, A new type of fixed point theorem in metric spaces,Nonlinear Anal., 71(11), (2009), 53135317.

[22] Y. Enjouji, M. Nakanishi and T. Suzuki, A generalization of Kannan's fixed point theorem, Fixed Point Theory and Appl., vol. 2009,Art.ID 192872, (2009), $10 \mathrm{pp}$ 